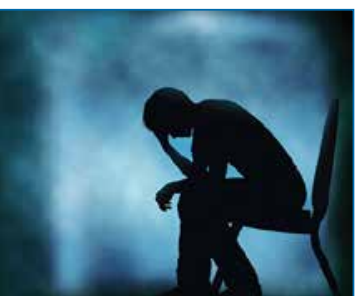

"So far, the

efficacy

and safety

of repeated

dosing has not

been tested

in placebo-

controlled

trials"

Colleen Loo MB BS, MD, FRANZCP

University of New South Wales Sydney, NSW.

colleen.loo@unsw.edu.au

doi: $10.5694 / \mathrm{mjal} 5.00966$

\title{
Is ketamine ready to be used clinically for the treatment of depression?
}

\author{
A single dose of ketamine produces rapid antidepressant effects, but attaining \\ lasting remission remains a challenge
}

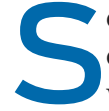

ome clinics in Australia and overseas have begun offering a course of ketamine treatments to patients with depression. However, this practice is premature, given that the efficacy and safety of this treatment approach has yet to be tested in controlled trials. Further, whether such a treatment approach leads to lasting response - that is, clinically meaningful effects - is as yet unknown. Ketamine differs from current antidepressant medications in that it acts primarily on the glutamate signalling system, rather than on the monoaminergic (eg, serotonin, noradrenalin) system. To date, eight randomised, placebo-controlled trials involving almost 200 participants with depression have shown robust antidepressant effects after a single, subanaesthetic dose of ketamine. ${ }^{1,2}$ These impressive clinical results have generated intense interest among researchers, clinicians and patients.

First, the onset of effects is much more rapid for ketamine than for other antidepressant treatments, with peak effects seen 24 hours after receiving a single treatment, in contrast with the several weeks required for most other treatments. Second, ketamine has a very high efficacy, as demonstrated by high overall remission rates, ${ }^{1}$ efficacy even in patients who are highly treatment resistant, ${ }^{3}$ and one preliminary report of superior efficacy to electroconvulsive therapy, typically considered the most effective proven biological treatment for depression. ${ }^{4}$ These observations have driven public demand for ketamine to be immediately made available as a clinical treatment for depression. ${ }^{5}$

However, a major drawback of this otherwise impressive treatment is that antidepressant effects typically last for only several days after a single treatment. ${ }^{6}$ The occasional patient may attain a lasting remission after a single dose; ${ }^{7}$ but, as yet, there is no way of identifying which patients will gain lasting benefit from a single treatment. Several strategies have been trialled in attempts to prolong the antidepressant effects of ketamine, but none have resulted in lasting improvement. The main strategy has been to give repeated doses of ketamine. Preliminary trials suggest this may prolong the antidepressant effects from a few days to a few weeks. ${ }^{8}$ So far, the efficacy and safety of repeated dosing has not been tested in placebo-controlled trials.

Risks of acute treatment with ketamine include induction of psychotomimetic effects and elevation of blood pressure. These are transient, occurring mainly in the first hour after treatment. Ketamine has been given safely to patients in clinical trials, in which patients were first carefully assessed in terms of hypertension, cardiac function, hepatic function and psychiatric illness, and with careful monitoring and constant supervision in the immediate hours after treatment. Longer-term use is associated with different risks, and the safety of ketamine with repeated treatments is unclear. Data on chronic use come largely from recreational users; that is, the data are unsystematic and uncontrolled. What evidence there is suggests a risk of hepatic impairment, bladder dysfunction and, possibly, cognitive impairment. ${ }^{9}$ Until there are clear data on these risks, repeated treatment doses should be given within a framework of systematic evaluation of these adverse effects. Another important consideration is the risk of inducing craving for further ketamine in patients treated with the drug. Although research participants evaluated 6 months after participation in strictly controlled treatment trials for depression have not shown increased craving for ketamine, there is a cautionary report of ketamine tolerance and addiction developing after its use to treat depression. ${ }^{10}$ In this report, increasing doses of ketamine were used in an attempt to obtain lasting antidepressant effects, resulting in considerable adverse effects and eventual requirement for detoxification from ketamine, with resultant lapse into severe depression.

Other considerations in the use of ketamine as a treatment for depression include the optimal route of administration and dosage. Most clinical trials to date have administered $0.5 \mathrm{mg} / \mathrm{kg}$ ketamine over a 40 -minute intravenous infusion. Ketamine has also been given by simpler methods: orally or sublingually, by intramuscular or subcutaneous injection, and by intranasal spray, with some studies reporting similar results to studies using an intravenous route. ${ }^{711-13}$ It is also unclear whether $0.5 \mathrm{mg} / \mathrm{kg}$, the dose selected for initial trials and used in most subsequent trials, is the optimal dose level. To date, there have been minimal investigations of the important pharmacodynamic considerations of treatment route and dosage, and how these may determine the magnitude and persistence of the antidepressant response.

Given the current evidence and risk of potential harm, it is not surprising that recent actions have been taken by health authorities in Australia to curtail medical practitioners offering a course of ketamine treatments to patients with depression. ${ }^{14}$ If ketamine is prematurely applied clinically to treat depression, before research has determined how (and if) it can be effectively and safely used to achieve lasting remission of depression, the end result may be disillusionment and even abandonment of this otherwise promising therapy.

Competing interests: No relevant disclosures.

Provenance: Commissioned; externally peer reviewed.

(c) 2015 AMPCo Pty Ltd. Produced with Elsevier B.V. All rights reserved.

References are available online at www.mja.com.au. 
1 McGirr A, Berlim MT, Bond DJ, et al. A systematic review and meta-analysis of randomized, double-blind, placebocontrolled trials of ketamine in the rapid treatment of major depressive episodes. Psychol Med 2015; 45: 693-704.

2 Lai R, Katalinic N, Glue P, et al. Pilot dose-response trial of I.V. ketamine in treatment-resistant depression. World J Biol Psychiatry 2014; 15: 579-584.

3 Ibrahim L, Diazgranados N, Luckenbaugh DA, et al. Rapid decrease in depressive symptoms with an $\mathrm{N}$-methyl-daspartate antagonist in ECT-resistant major depression. Prog Neuropsychopharmacol Biol Psychiatry 2011; 35: 1155-1159.

4 Ghasemi M, Kazemi MH, Yoosefi A, et al. Rapid antidepressant effects of repeated doses of ketamine compared with electroconvulsive therapy in hospitalized patients with major depressive disorder. Psychiatry Res 2014; 215: 355-361.

5 Arbusson K. Alarm over experimental ketamine treatment. Australian Doctor 2015; 16 Feb. http://www.australiandoctor. com.au/News/Latest-News/Alarm-over-experimentalketamine-treatment (accessed Oct 2015).

6 Zarate CA Jr, Singh JB, Carlson PJ, et al. A randomized trial of an N-methyl-D-aspartate antagonist in treatment-resistant major depression. Arch Gen Psychiatry 2006; 63: 856-864.

7 Galvez V, O'Keefe E, Cotiga L, et al. Long-lasting effects of a single subcutaneous dose of ketamine for treating melancholic depression: a case report. Biol Psychiatry 2014; 76: el-e2.

8 Murrough JW, Perez AM, Pillermer S, et al. Rapid and longerterm antidepressant effects of repeated ketamine infusions in treatment-resistant major depression. Biol Psychiatry 2013; 74: 250-256.

9 Katalinic N, Lai R, Somogyi A, et al. Ketamine as a new treatment for depression: a review of its efficacy and adverse effects. Aust N Z J Psychiatry 2013; 47: 710-727.

10 Bonnet U. Long-term ketamine self-injections in major depressive disorder: focus on tolerance in ketamine's antidepressant response and the development of ketamine addiction. J Psychoactive Drugs 2015; 47: 276-285.

1 Lapidus KA, Levitch CF, Perez AM, et al. A randomized controlled trial of intranasal ketamine in major depressive disorder. Biol Psychiatry 2014; 76: 970-976.

12 Chilukuri H, Reddy NP, Pathapati RM, et al. Acute antidepressant effects of intramuscular versus intravenous ketamine. Indian J Psychol Med 2014; 36: 71-76.

13 Lara DR, Bisol LW, Munari LR. Antidepressant, mood stabilizing and procognitive effects of very low dose sublingual ketamine in refractory unipolar and bipolar depression. Int $\mathrm{J}$ Neuropsychopharmacol 2013; 16: 2111-2117.

14 Worthington E. Ketamine injections: AHPRA bans former Aura Medical director Graham Barrett from prescribing drug amid investigation. ABC News. 16 Jun 2015. http://www.abc.net. au/news/2015-06-16/ketamine-injections-graham-barrettbanned-from-prescribing-drug/6550804 (accessed Oct 2015). 